\title{
Nicarbazin has no effect on reducing feral pigeon populations in Barcelona
}

Juan Carlos Senar ${ }^{1}$, Helena Navalpotro ${ }^{1}$, Jordi Pascual ${ }^{1,2}$ and Tomás Montalvo².

${ }^{1}$ Museu de Ciències Naturals de Barcelona, Castell dels Tres Dragons, Parc Ciutadella, $P^{o}$ Picasso s/n, 08003 Barcelona, Spain

${ }^{2}$ Agencia de Salut Publica de Barcelona, and CIBER de Epidemiología y Salud Pública, Av.Príncep d'Astúries 63, 3r.2a, 08012 Barcelona, Spain

Corresponding author: Juan Carlos Senar. +34.616737695, jcsenar@bcn.cat

Juan Carlos Senar:jcsenar@bcn.cat https://orcid.org/0000-0001-9955-3892

Helena Navalpotro: helena.navalpotro@gmail.com

Jordi Pascual: jpascualsala@gmail.com

Tomas Montalvo: tmontal@aspb.cat

This article has been accepted for publication and undergone full peer review but has not been through the copyediting, typesetting, pagination and proofreading process which may lead to differences between this version and the Version of Record. Please cite this article as doi: $10.1002 / \mathrm{ps} .6000$

This article is protected by copyright. All rights reserved. 


\begin{abstract}
BACKGROUND: Nicarbazin is an anti-coccidial product sometimes used as a contraceptive to reduce the size of feral pigeon populations. However, its effectiveness in reducing pigeon population size in cities has generated some controversy. Here, we evaluate its effectiveness in Barcelona city.
\end{abstract}

RESULTS: We set 23 feeding stations in which we provided nicarbazin and 10 feeding stations with a placebo (untreated corn). Censuses were carried out before and after one year of treatment, in radii of $200 \mathrm{~m}$ around each feeder. We additionally censused 28 circles of $200 \mathrm{~m}$ of radius distributed randomly $200 \mathrm{~m}$ away from the feeders and 28 circles distributed $>500 \mathrm{~m}$ away from the feeders, which acted as controls. Population size across the whole city was also evaluated pre- and post-treatment. We found that feral pigeon density did not change after one year of treatment, either in the circles around feeding stations with nicarbazin or in the areas around control stations distributed at 200 and $>500 \mathrm{~m}$ from the feeders. Population size in placebo circles rose after a year by $10 \%$. The pigeon census for the whole city of Barcelona showed a $10 \%$ increase.

CONCLUSION: Overall, our results indicate that the nicarbazin treatment had no effect on the feral pigeon population size, and we advise against its use as a pigeon control method, at least in large cities.

Keywords: Feral pigeon, Columba livia; nicarbazin; contraceptives; population size control 


\section{Introduction}

Feral pigeon (Columba livia var domestica) is one of the many species affected positively by human activities. High reproduction rates determined by availability of unlimited food and suitable nesting sites near humans enable feral pigeon populations to thrive in urban environments, causing problems such as major disease risk and building damage ${ }^{1-3}$. These issues require governments to undertake control methods against the species.

In Barcelona city (NE Spain), pigeons were traditionally caught and removed in places where high densities were a public health problem ${ }^{4}$. However, this method was not effective in the short-term due to the rapid colonization by young pigeons in areas where birds were removed ${ }^{5}$. After 2006, massive captures were undertaken and the population was successfully reduced ${ }^{6}$, but controversy arose around the ethics of this method. This pushed the Barcelona Council to look for alternative and ethical pigeon control methods.

One of these methods is the administration of an anti-fertility drug, which reduces breeding success. Nicarbazin is the contraceptive product most commonly used. This ingredient was originally employed to treat coccidiosis in birds ${ }^{7}$. Nicarbazin is an equimolar complex formed by 4,4'-dinitrocarbanilide (DNC) and 2-hydroxy-4,6dimethylpyrimidine (HDP). The function of the HDP is to increase the absorption of the material in the intestine, while the DNC is the active anticoccidial drug ${ }^{8,9}$. Nicarbazin has the ability to reduce the production of eggs because it interferes in cholesterol metabolism, which affects the formation of the vitreous membrane breaking the separation between egg yolk and egg white ${ }^{10,11}$.

We refer to the product based on nicarbazin, used in Europe to control pigeon populations, as NP1 (see material and methods section). NP1 consists of corn seeds covered with nicarbazin (800 ppm) and with a water-repellent film. However, its effectiveness has generated some controversy. In studies conducted with captive 
pigeons, Martelli et al. ${ }^{12}$ reported a high success of a different nicarbazin product (not NP1) in in reducing the fertility of pigeons in highly controlled situations. Meanwhile, Giunchi et al. ${ }^{13}$ reported a very low effectiveness of NP1, which was attributed to the low palatability of the product. Field studies have also provided unconvincing results. Some studies comparing the abundance of pigeons before and after the treatment found a reduction in the population ${ }^{14,15}$. Nevertheless, the results may not be reliable since control parcels were not considered. In addition, the two censuses were carried out at different times of year, a factor affecting pigeon detectability and density ${ }^{5,16-18}$. In another study in the city of Modena, control zones were not considered and a restriction of the nesting sites was simultaneously applied in the same period ${ }^{19}$. This made it impossible to discern the effects of nicarbazin from nesting site limitation, which we know from other cities to have an effect ${ }^{20}$. In a study carried out in the large city of Genova, controlled areas were considered, but pigeons were counted only around the feeders ${ }^{21}$. The reduction of pigeons observed may have been due to a loss of interest in the feeders or to other collateral factors. In summary, the effectiveness of NP1 in reducing feral pigeon populations, especially in large cities, remains unclear.

Our aim was to analyze the effectiveness of NP1 as a pigeon control method in a large city, namely Barcelona, where the species maintains very high densities ${ }^{4,22}$. To avoid the methodological problems already mentioned, we established different levels of study to take into account the evolution of population over time and space. Temporary effects were tested by comparing censuses both before and after NP1 treatment. Spatial effects were analyzed by comparing censuses carried out in circles located at different distances from NP1 dispensers. We established an additional control treatment by providing placebo (i.e. non-treated corn) in some of the dispensers, which when compared with the experimental circles should allow us to discern the effect of nicarbazin from the effect of corn provision. 
Considering that our main objective was to determine whether the treatment with NP1 had an effect on the total population size of pigeons in Barcelona, a global census was carried out simultaneously before and after the NP1 treatment. The census employed the same methodology and the same sampled areas as in previous years 4, 17, 23, 24 .

Our main null hypothesis was that the treatment with NP1 would reduce the feral pigeon population size and density, and that this effect should be mainly seen within a radius of about $200 \mathrm{~m}$ from NP1 dispensers, since pigeons in Barcelona city generally seem to move less than this distance ${ }^{5,25}$. According to this hypothesis, and according to the experimental design used, we predicted that, after one year of treatment with NP1: 1) Experimental circles with NP1 treatment should show a reduction in population size; 2). On the contrary, placebo circles baited with untreated corn should show an increase in population size; 3) Population size decrease should be higher in experimental circles than in control circles located at increasing distances from dispensers; and 4) Global population size in the whole city of Barcelona should decline from the first to the second census.

\section{Materials and methods}

In Europe, the product based on nicarbazin is Ovistop (C) ${ }^{26}$, which in spite of not having been approved in Europe as a biocide, is commonly used as an anti-fertility drug to control pigeon populations. We will refer to it as NP1. The American counterpart is Ovocontrol (c) ${ }^{27}$, and we will refer to it as NP2.

The study was carried out in Barcelona city during 2017 and 2018. From March 2017 to February 2018 (treatment period), 23 feeding stations (i.e. dispensers) provided NP1 and 10 feeding stations provided placebo (untreated corn) in different districts of 
Barcelona. We chose an unbalanced design to favour stations with treatment and thus increase the chances of sterilization of the population. Dispensers were settled in areas of high pigeon density (Figure 1), determined from previous knowledge on the distribution and density of pigeons in the city. The assignment of dispensers with and without (placebo) treatment was determined at random. Dispensers measured 110 $\mathrm{cm}$ high and $45 \mathrm{~cm}$ in diameter, and had the shape of a typical paper bin. Each dispenser held about $30 \mathrm{~kg}$ of corn. Dispensers released automatically about one $\mathrm{kg}$ of food each day, $2-3 \mathrm{~m}$ around the feeder. The time to release the food was $<5 \mathrm{sec}$. Food was released at 8:00h from March to June, and at 7:00h in other months of the year. See Ovistop guidelines ${ }^{26}$ and Lavín \& González-Crespo ${ }^{28}$ for more details on the dispensers and their operation. We placed one feeder per feeding station, except in the case of 8 NP1 feeding stations in areas with a high density of pigeons where we placed two feeders to provide a greater amount of treated food. Pigeons were baited with untreated corn from 16th February to 26th March to acclimate them to the feeders. We estimate that during the study period about 9,000 $\mathrm{kg}$ of treated corn and about 4,000 kg of untreated corn were released into the city. The company Zooethics (previously Ambiens) installed the feeders and was in charge of the entire operation, including maintenance of the dispensers as well as the supply and control of the consumption of the drug, following the Ovistop guidelines.

To determine the effect of NP1, we censused the pigeons inside circles located at different distances from the feeding stations, in pre- and post-treatment periods. Censuses were carried out in circles of $200 \mathrm{~m}$ radius around each feeder. In feeding 
stations with two feeders, we had two circles centered on each feeder drawing an eightshaped polygon. The area of circles was 12.5 ha (greater in eight-shaped polygons). Hence, we censused 23 treatment circles ( 8 of them eight-shaped) and 10 placebo circles. We also censused 28 circles distributed randomly $200 \mathrm{~m}$ away and 28 circles distributed randomly $>500 \mathrm{~m}$ away from the treatment feeders (Figure 1 ). The number of censuses was therefore 89 in 2017, and the same circles were censused in 2018. Censuses were carried out from $18^{\text {th }}$ November to $15^{\text {th }}$ February, a period when pigeon breeding activity is lowest ${ }^{29}$. Zooethics changed the exact location of some of the feeders just prior to the study period, to better accommodate the urban setting, with feeders moved from 5 to $184 \mathrm{~m}$ from their original locations. We therefore had to repeat the census in these "new" circles, which delayed the end of censuses to 22 March. To remove any possible seasonal effect, the pre- and post-treatment monitoring at each circle was carried out during the same Julian dates in 2017 and 2018

Estimations of the total pigeon population size in the city of Barcelona (with an urban area of $64.57 \mathrm{~km}^{2}$ ) were made using the square count method ${ }^{30,31}$, following the same methodology as in 1991, 2007, 2011, 2015 and 2017 4, 6, 17, 32, 33. We divided the city into 200 squares of $550 \times 550 \mathrm{~m}^{6,17}$ (i.e. total census area: $60.5 \mathrm{~km}^{2}$ ), excluding Collserola and Zona Franca due to their very low pigeon densities ${ }^{24}$. In the previous census, starting in the 1980's, we used a map of Barcelona where the squares were drawn by hand. Now, we have taken advantage of GIS and drawn squares using QGIS; this resulted in one of the squares on the right side of the map to be outside of Barcelona, when in the past there was some overlap with the city. We chose not to exclude this square, as this would cause a mismatch with comparisons to the previous census. We should also note that the square was not actually censused, but only forms part of the layout of the city. The pre- treatment global census was carried out from $16^{\text {th }}$ November 2016 to $7^{\text {th }}$ February 2017 (hereafter, the 2017 census), and the post-treatment global census was carried out on the same dates of the following year (hereafter, the 2018 census). Each 
square was censused in the two years on the same Julian date ( \pm 1 day) to avoid biases from seasonal or other effects. We monitored 67 randomly selected squares to cover $33.5 \%$ of the total census area $\left({ }^{24}\right.$; Figure 2 ). To obtain a more accurate estimation, we followed a simple random stratified sampling ${ }^{34}$ by classifying the squares in three strata ${ }^{6}$ : S1) Peripheral areas of the city with low pigeon densities; S2) Areas with medium densities; and S3) Old town areas with the highest pigeon densities (Figure 2). This method allowed us to improve the precision of our estimates ${ }^{17}$.

Sampled circles and squared areas were surveyed by walking along all streets, roads and parks counting all visible pigeons in the shortest time. Censuses were carried out between two hours before and two hours after noon (solar time), corresponding to the peak pigeon activity ${ }^{24}$. Although this higher activity increased the likelihood of double counts, it also increased the probability of detection. To reduce the probability of counting the same pigeons (i.e. double counts), censuses were carried out by walking in one direction ${ }^{17}$.

To avoid underestimation caused by undetected birds, we applied to squares a correction factor of 3.5 to the sum of pigeons counted, which is a robust factor of detectability obtained in three different studies (Pavia ${ }^{20}$ and Barcelona in $1991{ }^{17}$ and $2011^{33}$ ). Density of pigeons inside each square was calculated by counting the number of observations, multiplying by the correction factor and dividing by the sampled area. The area of squares was 30.25 ha (smaller in the squares partially on the coast). This procedure additionally allowed us to compare current census data to values obtained from the previous census in Barcelona ${ }^{4,17}$. This correction factor was not used in the case of circles, since here we were only interested in relative counts.

For the statistical analysis, we used the program Statistica (Statsoft, Inc). The density of pigeons for all circles was compared between the different treatments (experimental, placebo, control 200 and control 500) and between the pre- and post-treatments. Data 
were analyzed using an ANOVA. We compared the same circles pre-treatment and posttreatment using a paired analysis (Repeated Measures ANOVA). The variables pigeon density in 2017 and pigeon density in 2018 were considered dependent variables while the treatment was a categorical factor. Planed comparison tests (PC) were used to test predictions related to variations in pigeon density according to different treatments (see introduction). Data on pigeon density in the circles showed asymmetry to the right (skewness), assimilating to a Poisson distribution (Distribution Fitting: $\mathrm{X}^{2}{ }_{2}=25, \mathrm{p}<0.01$ ). Logarithm transformation over corrected the data, which still did not fit to a normal distribution (Shapiro-Wilk test; 2017: $W=0.973, p=0.07 ; 2018: W=0.967, p=0.02$ ), and Levene's Test for Homogeneity of Variances was still significant (2017: $F_{3,84}=2.93$, $\left.p=0.04 ; 2018: F_{3,84}=3.42, p=0.02\right)$. In these cases, the square root transformation is advised ${ }^{35-39}$. The square root transformed data fit to a normal distribution and showed homogeneity of variances (Shapiro-Wilk test, 2017: $W=0.983, p=0.33 ; 2018: W=0.979$, $p=0.16$; Levene's Test, 2017: $\left.F_{3,84}=0.43, p=0.73 ; 2018: F_{3,84}=0.04, p=0.99\right)$, and thus we used this transformation.

Previous work to validate the effect of NP1 used pigeon counts in the area just around each feeder ${ }^{21}$. At the same time that we were carrying out our study, Lavín \& GonzálezCrespo ${ }^{28}$ analyzed the abundance of pigeons at the feeding stations by counting the number of pigeons seen around the dispensers just before releasing the food, when the corn was released, and afterward. They used as count data the higher figure from these three counts (see ${ }^{28}$ for more details). Initial pre-treatment counts at the different experimental and placebo feeders were carried out from $15^{\text {th }}$ February to $26^{\text {th }}$ March 2017, just when the feeders distributed untreated bait to acclimate the birds to the feeders (see above) ${ }^{28}$. Final post-treatment counts were carried out from $1^{\text {st }}$ to $30^{\text {th }}$ November 2017. We correlated data from our census at $200 \mathrm{~m}$ radius circles around each feeder with the counts at the feeders by Lavín \& González-Crespo ${ }^{28}$, for both pre- 
and post-treatment periods. If counts at feeders truly reflected pigeon population size, the two counts should be correlated.

The estimation of the total pigeon population size in the city of Barcelona was calculated by using the average number of pigeons per square for each strata, multiplying it by the correction factor (i.e. 3.5) and extrapolating it to the 200 squares in which the Barcelona urban area was divided. The density of pigeons per square was also compared between the two years of study using a Repeated Measures ANOVA analysis, hence using a paired analysis approach. Pigeon density in the squares adjusted to a normal distribution $\left(\mathrm{X}^{2}{ }_{2}\right.$ $=3.89, p=0.14)$, and hence no transformation was needed.

\section{Results}

Analyses showed that overall, and after one year of treatment, the density of pigeons in the circles slightly increased by $10 \%$ (from $7.7 \pm 0.59$ (SE) to $8.6 \pm 0.79$ (SE) individuals per ha; Repeated Measures ANOVA, Factor Year: $F_{1,84}=5.90, p=0.02$; Treatment: $F_{3,84}=14.28$ $p<0.001$; Year $x$ Treatment: $F_{3,84}=1.97, p=0.13$;). Pigeon population size in experimental circles remained the same after one year of treatment with NP1 (PC: $F_{1,84}=1.41, p=0.24$; Figure 3). The same was found for control circles at $200 \mathrm{~m}$ (PC: $F_{1,84}=0.80, p=0.37$ ) and at $>500 \mathrm{~m}$ ( $\left.P C: F_{1,84}=0.21, p=0.65\right)$. The interaction Year $x$ Treatment, considering these three treatments, was not significant $\left(F_{2,75}=0.76, p=0.47\right)$, which means that circles treated with NP1 behaved in the same way as control circles with no treatment. However, in the placebo circles, where untreated corn was provided, pigeon population size increased by about a $10 \%$ ( $P C$ : $F_{1,84}=6.41, p=0.01$; Figure 3 ). Pigeon density was higher in feeding station circles (nicarbazin and placebo) than in control circles (Factor Treatment, $P C$ comparing feeding circles vs. control circles: $F_{1,84}=40.40, p<0.001$; Figure 3), since feeding stations were a priori placed in the areas of the city with higher densities. 
Pigeon counts pre- and post-treatment at NP1 feeders showed a reduction in the number of pigeons feeding of a $25 \%$ (2017: 117 \pm 12.4 SE, 2018: 87 \pm 11.2 SE pigeons; PC from RM ANOVA for NP1 feeders: $F_{1,31}=16.22, p<0.001$; data from Table 7 in ${ }^{28}$ ). Counts at placebo feeders did not change (2017: $97.5 \pm 18.8$ SE, 2018: $100.5 \pm 16.9$ pigeons; PC from RM ANOVA for placebo feeders: $F_{1,31}=0.03, p=0.87$ ). However, pigeon counts obtained from census data in circles around each feeder was not correlated with count data taken immediately around each feeder, both for pre-treatment $\left(r=0.10, t_{31}=0.58\right.$, $p=0.56)$ and post-treatment data $\left(r=0.29, t_{31}=1.67, p=0.10\right)$.

The global population size of pigeons in the city of Barcelona increased by $9.5 \%$ after one year of treatment, from 103,226 $\pm 14,353$ individuals in 2017 to $113,048 \pm 13,957$ individuals in $2018(95 \% \mathrm{Cl})$. The increase in density of pigeons within each square was significant (Repeated Measures ANOVA: $F_{1,64}=.09, p=0.02$ ) and was independent of the strata (interaction Year $x$ Strata: $F_{2,64}=0.04, p=0.96$ ). This latter finding is interesting, since pigeon density highly varied according to the strata (Repeated Measures ANOVA: $F_{2,64}=13.5, p<0.001$ ), implying that the increase in pigeon density was not influenced by the initial density of pigeons and the geographical area of the city.

\section{Discussion}

Results show that none of the predictions supporting the effectiveness of NP1 to reduce feral pigeon population size hold. One year of treatment with NP1 in experimental circles did not reduce the feral pigeon density. Since experimental and control circles (at 200 and $>500 \mathrm{~m}$ ) behaved in the same way, we can stress that NP1 had no effect on pigeon density. The global increase $(9.5 \%)$ in pigeon population density in the whole city of Barcelona again confirms that NP1 was ineffective in reducing pigeon density across the city. This increase, when compared to the previous increase in the population size observed from 2015 to 2017 (a 17\%), stresses that the pigeon population size in the city 
increased continuously after the cessation of the massive captures in $2015^{6}$. This increase is probably the result of a high availability of food in the city, in part provided by the public ${ }^{40}$, such that pigeon population size has not yet attained its carrying capacity. The fact that in 2006 the feral pigeon population size in Barcelona reached 256,000 pigeons ${ }^{4}$, stresses that population size could still increase in the coming years. Here, we should also stress that pigeons living in a city are a single management unit ${ }^{3}$, 5, 41 and thus a local reduction of density would be compensated for by dispersing pigeons that will rapidly colonize the area.

Our prediction related to placebo circles, where untreated corn was provided, was upheld, since population density increased by $10 \%$, a similar value to the increase estimated for the pigeon population size of all the city of Barcelona.

Pigeon counts pre- and post-treatment at NP1 feeders showed a reduction in the number of pigeons feeding of a $25 \%$. However, pigeon density in $200-m$-radius circles around each feeder did not correlate with these pigeon counts at the feeders, implying that they were poor density estimators. The suggestion in previous tests of NP1 that a reduction with time in bird counts at experimental feeders reflected a reduction in population size ${ }^{21,28}$ was therefore likely wrong. This result cautions against the use of counts at feeders to test the effectiveness of contraceptive food.

Reductions in count data at the feeders could simply be measuring a decreasing level of interest in the feeders among pigeons. NP1 is made of corn seeds covered with nicarbazin and coated with a water-repellent external film, which seems to make this food unpalatable to the birds ${ }^{13}$. The finding that captive birds fed with NP1 declined in physical condition as a consequence of avoiding the food ${ }^{13}$ supports this view. Since pre-treatment counts were carried out when providing untreated corn as bait, while post-treatment counts were made when providing NP1, the lower palatability of this latter product could easily explain a reduction in count data at feeders. 
NP1 treatment may not have had an effect on pigeon density due to both to its unpalatability and to a lack of effectiveness of the nicarbazin per se. This effectiveness was first evaluated in captivity by Martelli et al. ${ }^{12}$, who reported that in nicarbazin concentrations of $400 \mathrm{ppm}$ pigeon fertility declined to zero. In addition, Avery et al. ${ }^{27}$ achieved a $60 \%$ reduction in the number of chicks produced by applying nicarbazin concentrations of 5000 ppm. However, Giunchi et al. ${ }^{13}$ only achieved a $13 \%$ reduction with NP1 $(800 \mathrm{ppm})$, while they achieved a $48 \%$ reduction with pellets with the same concentration of nicarbazin (but with a higher palatability). This indicates that nicarbazin provided with palatable food (but not with NP1) can be effective in captivity situations where animals are forced to ingest it.

Since the lack of effects of NP1 on pigeon density in Barcelona cannot be tied to the effectiveness of nicarbazin per se, there may be issues related to the implementation of this product in cities. The lower palatability of NP1 compared to "natural" food ${ }^{13}$ could prevent females from reaching the necessary nicarbazin blood levels to reduce fertility 13. On the other hand, the timing of NP1 release in dispensers (just before sunrise) could prevent females from eating enough of this food, since in Basel they were found to remain in the nest until mid-morning ${ }^{42}$. Clearly, more exhaustive and individualized monitoring of the population of pigeons is necessary to understand in detail the effect of nicarbazin and how it should be provided. We advise, for example, an analysis of nicarbazin blood levels of male and female adult pigeons feeding at and around the feeding stations, and tracking of their movements with GPS devices.

Based on our results, we consider NP1 to be an inappropriate product to control the Barcelona feral pigeon population. Another anti-fertilizer drug like NP2 may function better given its greater palatability and higher nicarbazin dose. However, this control method is very costly because its application must be permanent to be effective ${ }^{43}$. In some models, it was estimated that when the treatment with nicarbazin is interrupted, the capacity of the population to recover is very high ${ }^{13,44}$. The use of nicarbazin in urban 
environments could additionally entail side effects in the urban food chain if consumed by non-target species ${ }^{45}$.

Consequently, pigeon control methods based on reducing the carrying capacity of the urban habitat, mostly focusing on reducing the availability of food and nesting sites 1,3 , 13, 46 should be prioritized. In Barcelona, a program of public education intended to reduce the availability of food provided by humans to pigeons was carried out in 2009. After one year, the population of these birds in the experimental area was reduced by $40 \%$ compared to the control zone ${ }^{40}$. The same method had been used in the 1990's in the city of Basel with similar results ${ }^{47,48}$. In some respects, this method works as a contraceptive method since reducing food availability significantly reduces breeding success ${ }^{46}$. A second approach is a reduction in the presence of appropriate breeding holes for pigeons ${ }^{49}$. This method obtained good results in the city of Pavia ${ }^{20}$, where rehabilitation programs in the oldest suburbs of the city reduced the pigeon population 50. The combination of the two methods should therefore provide a good approach.

\section{Conclusion}

Our results suggest the application of nicarbazin across a large spatial extent was ineffective at controlling feral pigeon populations. Alternative ethical methods currently exist that appear to be more effective, efficient, and sustainable for controlling feral pigeon population size in large cities. However, as reviewed by Giunchi et al. ${ }^{3}$, an effective management policy for controlling feral pigeons should consider a balanced integration of different control methods, proper monitoring, and reliable modeling, with a strong emphasis on reducing the carrying capacity of the population.

\section{Acknowledgements}


This study was funded by the Ecology Commissioner (Comissionat d'Ecologia) from the Barcelona City Council. We thank Dimitri Giunchi and an anonymous referee for very helpful comments on an earlier version. We also thank Victor Peracho, from the Agencia de Salut Pública de Barcelona for his continuous support and help.

\section{REFERENCES}

1 Johnston RF and Janiga M, Feral pigeons, Oxford University Press, New York (1995).

2 Haag-Wackernagel $\mathrm{D}$ and Moch $\mathrm{H}$, Health hazards posed by feral pigeons. J. Infect. 48:307-313 (2004).

3 Giunchi D, Albores-Barajas YV, Baldaccini NE, Vanni L and Soldatini C, Feral Pigeons: Problems, Dynamics and Control Methods, in Integrated Pest Management and Pest Control - Current and Future Tactics, ed. by Soloneski S, InTech, Rijeka, Croatia, pp. 215-240 (2012).

4 Senar JC, Carrillo-Ortiz J, Arroyo L, Montalvo T and Peracho V, Estima de la abundancia de Palomas (Columba livia var.) de la ciudad de Barcelona, 2006 y valoración de la efectividad del control por eliminación de individuos. Arxius Misc. Zool. 4:62-71 (2009).

5 Sol D and Senar JC, Urban pigeon populations: stability, home range, and the effect of removing individuals. Can. J. Zool. 73:1154-1160 (1995).

6 Pascual J, Riba D and Senar JC, Cens de la població de coloms i altres aus urbanes a Barcelona. Barcelona: Museu de Ciències Naturals de Barcelona (2015).

7 Jones JE, Solis J, Hughes BL, Castaldo DJ and Toler JE, Production and egg-quality responses of White Leghorn layers to anticoccidial agents. Poult. Sci. 69:378387 (1990).

8 Cuckler AC, Malanga CM, Basso AJ and O'Neill RC, Antiparasitic Activity of Substituted Carbanilide Complexes. Science 122:244 (1955).

9 Rogers EF, Brown RD, Brown JE, Kazazis DM, Leanza WJ, Ostlind DA and Rodino TM, Nicarbazin complex yields dinitrocarbanilide as ultrafine crystals with improved anticoccidial activity. Science 222:630-632 (1983).

10 Yoder CA, Graham JK and Miller LA, Molecular effects of nicarbazin on avian reproduction. Poult. Sci. 85:1285-1293 (2006). 
11 Sherwood DH, Milby TT and Higgins WA, The effect of nicarbazin on reproduction in white rock breeder hens. Poult. Sci. 35:1014-1019 (1956).

12 Martelli P, Bonati L, Gelati A, Ferraresi M, Montella L, Corradi A and Zannetti G, Il controllo farmacologico delle nascite nel colombo: contributo sperimentale. Ann. Fac. Med. Vet. Parma 13:249-257 (1993).

13 Giunchi D, Baldaccini NE, Sbragia G and Soldatini C, On the use of pharmacological sterilisation to control feral pigeon populations. Wildl. Res. 34:306-318 (2007).

14 Bursi E, Gelati A, Ferraresi M and Zannetti G, Impiego della nicarbazina nel controllo della riproduzione del colombo randagio di città. Ann. Fac. Med. Vet. Parma 21:97-115 (2001).

15 Ferri M, Ferraresi M, Gelati A, Zannetti G, Ubaldi A, Contiero B and Bursi E, Use of Nicarbazinee in the control of urban pigeon colonies in Italy in 1990-2007. Ann. Fac. Med. Vet. Parma 29:91-102 (2009).

16 Ryan AC, The distribution, density, and movements of feral pigeons Columba livia and their relationship with people. Master Thesis: Victoria University, Wellington (2011).

17 Senar JC and Sol D, Censo de Palomas Columba livia var. de la ciudad de Barcelona: Aplicación del muestreo estratificado con factor de corrección. Butll. GCA 8:19-24 (1991).

18 Giunchi D, Gaggini V and Baldaccini N, Distance sampling as an effective method for monitoring feral pigeon (Columba livia $f$. domestica) urban populations. Urban Ecosyst. 10:397-412 (2007).

19 Ferri M, Ferraresi M, Gelati A, Zannetti G, Domenichini A, Ravizza L and Cadignani R, Control of the urban pigeon Columba livia population and the preservation of common swift Apus apus and bats Chiroptera during the restoration of the Ghirlandina tower in the city of Modena (Italy). Julius-KühnArchiv:133-135 (2011).

20 Barbieri $\mathrm{F}$ and Andreis $\mathrm{Cd}$, Indagine sulla presenza dei Colombi (Columba livia forma domestica) nel centro storico di Pavia e nell'oltrepo Pavese (U.S.L. N. 79, voghera). Richer. Biol. Selvaggina 17:195-198 (1991).

21 Albonetti P, Marletta A, Repetto I and Sasso EA, Efficacy of nicarbazin $\left(\right.$ Ovistop ${ }^{\circledR}$ ) in the containment and reduction of the populations of feral pigeons (Columba livia var. domestica) in the city of Genoa, Italy: A retrospective evaluation. Vet. Ital. 51:63-72 (2015).

22 Montalvo T, Pascual J, Senar JC and Peracho V, Colom roquer-Columba livia, in Atles dels ocells nidificants de Barcelona, ed. by Anton M, Herrando S, García D, 
Ferrer X, Parés M and Cebrian R, Ajuntament de Barcelona, Barcelona, pp. 9091 (2017).

23 Sol D and Senar JC, Comparison between two censuses of Feral pigeon Columba livia var. from Barcelona: an evaluation of seven years of control by killing. Butll. GCA 9:29-32 (1992).

24 Uribe F, Colom L, Camerino M, Ruiz J and Senar JC, Censo de las palomas semidomésticas (Columba livia var.) de la ciudad de Barcelona. Misc. Zool. 8:237-244 (1984).

25 Pascual J, Senar JC, Riba D and Carrillo-Ortiz J, Determinació de l'àrea de deambulació dels coloms a la ciutat de Barcelona. Barcelona: Museu de Ciències Naturals de Barcelona (2012).

26 Ovistop Ibérica, Anticonceptivo para palomas. Òdena (Barcelona). (2015).

27 Avery ML, Keacher KL and Tillman EA, Nicarbazin bait reduces reproduction by pigeons (Columba livia). Wildl. Res. 35:80-85 (2008).

28 Lavín S and González-Crespo C, Informe del Proyecto para la implantación del control de palomas mediante esterilización con nicarbacina en la ciudad de Barcelona. Informe Anual 2017. Bellaterra: Universidad Autónoma de Barcelona. (2018).

29 Uribe F, Senar JC, Colom L and Camerino M, Morfometría de las palomas semidomésticas (Columba livia var.) de la ciudad de Barcelona. Misc. Zool. 9:339-345 (1985).

30 Williams BK, Nichols JD and Conroy MJ, Analysis and Management of Animal Populations: Modeling, estimation, and decision making, Academic Press, New York, USA (2002).

31 Conroy MJ, Carroll JP, Senar JC and Thompson JJ, Métodos Cuantitativos para la Conservación de los Vertebrados, University of Nebraska, Lincoln, NE, USA (2015).

32 Senar JC, Pascual J and Riba D, Cens de la Població de Coloms de la ciutat de Barcelona 2010. Barcelona: Museu de Ciències Naturals de Barcelona. (2011).

33 Navalpotro $\mathrm{H}$ and Senar JC, Cens de la població de coloms a Barcelona: Fase pre-tractament amb Ovistop. Barcelona: Museu de Ciències Naturals de Barcelona (2017).

34 Tellería JL, Manual para el censo de los vertebrados terrestres, Editorial Raices, Madrid (1986).

35 Baguley T, Serious stats: A guide to advanced statistics for the behavioral sciences, Palgrave Macmillan, Basingstoke, U.K. (2012). 
36 Quinn GP and Keough MJ, Experimental design and data analysis for biologists, Cambridge University Press, Cambridge, UK (2002).

37 Osborne JW, Best practices in data cleaning: A complete guide to everything you need to do before and after collecting your data, SAGE, Thousand Oaks Calif. (2013).

38 Erickson $\mathrm{BH}$ and Nosanchuk TA, Understanding data, Open Univ. Press, Buckingham, U.K. (2009).

39 Guisande González C, Vaamonde Liste A and Barreiro Felpeto A, Tratamiento de datos con R, Statistica y SPSS, Ediciones Díaz de Santos, Madrid (2013).

40 Senar JC, Montalvo T, Pascual J and Peracho V, Reducing the availability of food to control feral pigeons: changes in population size and composition. Pest. Manag. Sci. 73:313-317 (2017).

41 Jacob G, Prévot-Julliard AC and Baudry E, The geographic scale of genetic differentiation in the feral pigeon (Columba livia): implications for management. Biol. Invasions 17:23-29 (2015).

42 Rose E, Haag-Wackernagel D and Nagel P, Practical use of GPS-localization of Feral Pigeons Columba livia in the urban environment. Ibis 148:231-239 (2006).

43 Massei G and Cowan D, Fertility control to mitigate human-wildlife conflicts: a review. Wildl. Res. 41:1 (2014).

44 Baldaccini NE and Giunchi D, Le popolazioni urbane di colombo: Considerazioni sulla loro genesi e sulle metodologie di gestione. Biologia Ambientale 20:125141 (2006).

45 Bynum KS, Yoder CA, Eisemann JD, Johnston JJ and Miller LA, Development of nicarbazin as a reproductive inhibitor for resident Canada geese. Wildlife Damage Management Conference 11:179-189 (2005).

46 Stock B and Haag-Wackernagel D, Food shortage affects reproduction of Feral Pigeons Columba livia at rearing of nestlings. Ibis 158:776-783 (2016).

47 Haag-Wackernagel D, Street pigeons in Basel. Nature 361:200 (1993).

48 Haag-Wackernagel D, Regulation of the Street Pigeon in Basel. Wildl. Soc. Bull. 23:256-260 (1995).

49 Haag-Wackernagel D and Geigenfeind I, Protecting buildings against feral pigeons. Eur. J. Wildl. Res. 54:715-721 (2008).

50 Sacchi L, Gentilli A, Razzetti E and Barbieri F, Effect of building features on density and flock distribution of feral pigeons Columba livia var. domestica in an urban environment. Can. J. Zool. 80:48-54 (2002). 


\section{Figures}

Figure 1. Map of Barcelona city showing the feeding stations with dispensers (dots show nicarbazin feeders, triangles show placebo feeders) and the different treatment circles (straight line for the area around feeders, discontinuous line for circles $200 \mathrm{~m}$ away from feeders and dotted line for circles $>500 \mathrm{~m}$ away from feeders).

Figure 2. Map of Barcelona city showing the sampled squares (stripped, $\mathrm{N}=67$ ) classified in different strata according to feral pigeon density: S1) low density in light gray; S2) medium density in gray; and S3) high density in dark gray.

Figure 3. Mean $( \pm S E)$ pigeon density, square root transformed, in circles of $200 \mathrm{~m}$ radius according to the year of census (pre-treatment, 2017; and post-treatment, 2018) and the different treatments (placebo, nicarbazin, control 200 and control 500). 


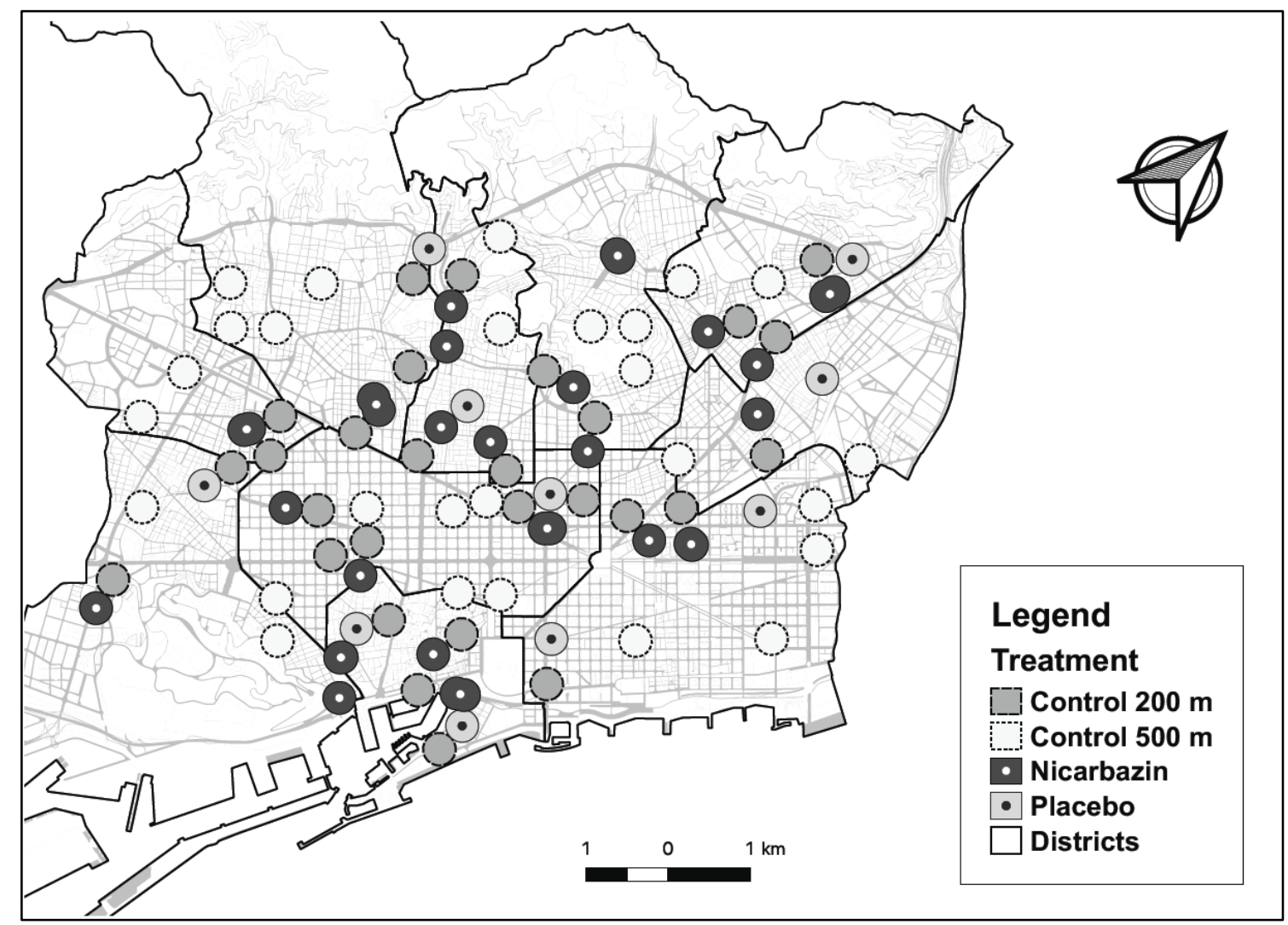

Figure 1.

This article is protected by copyright. All rights reserved. 


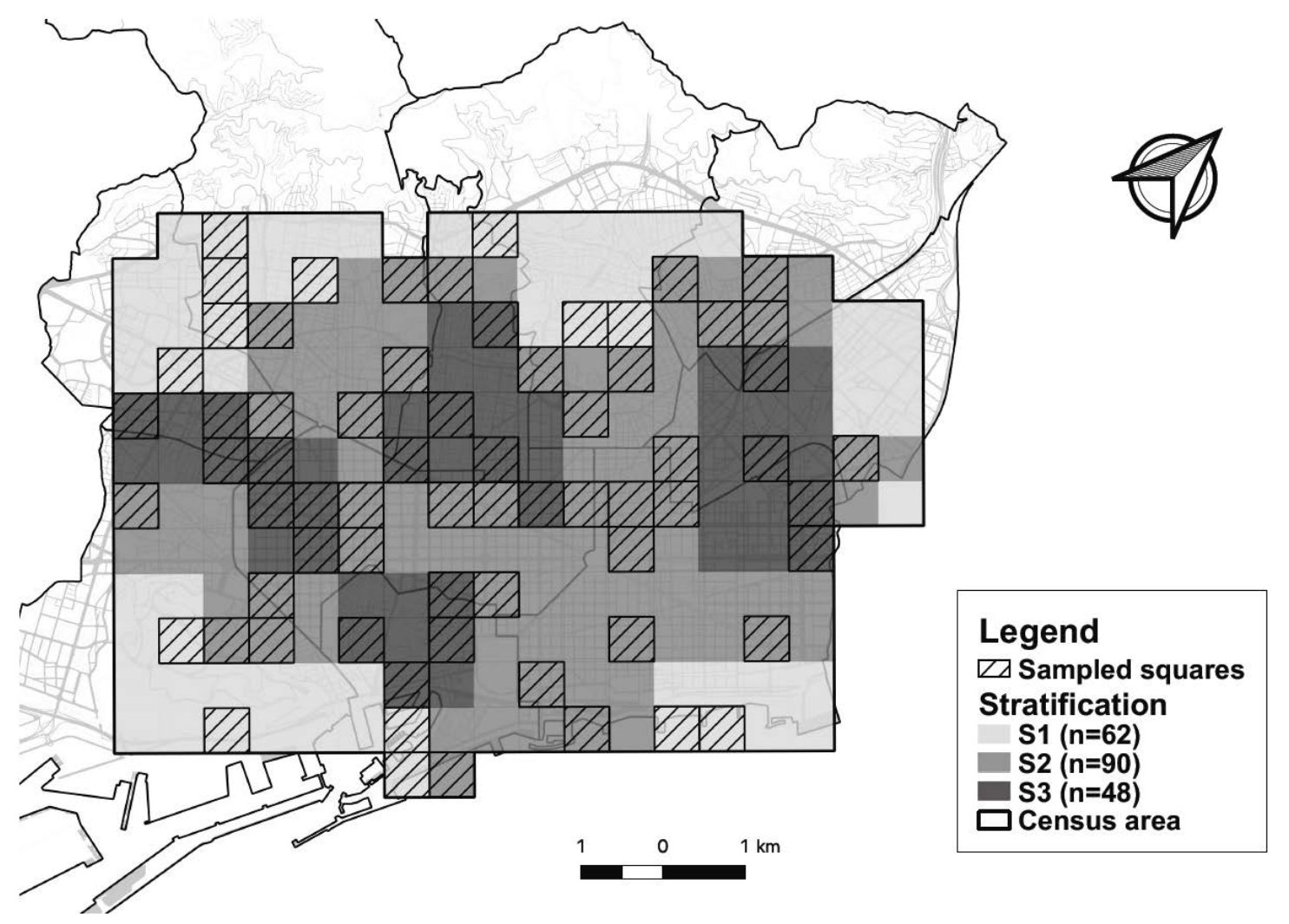

Figure 2. 


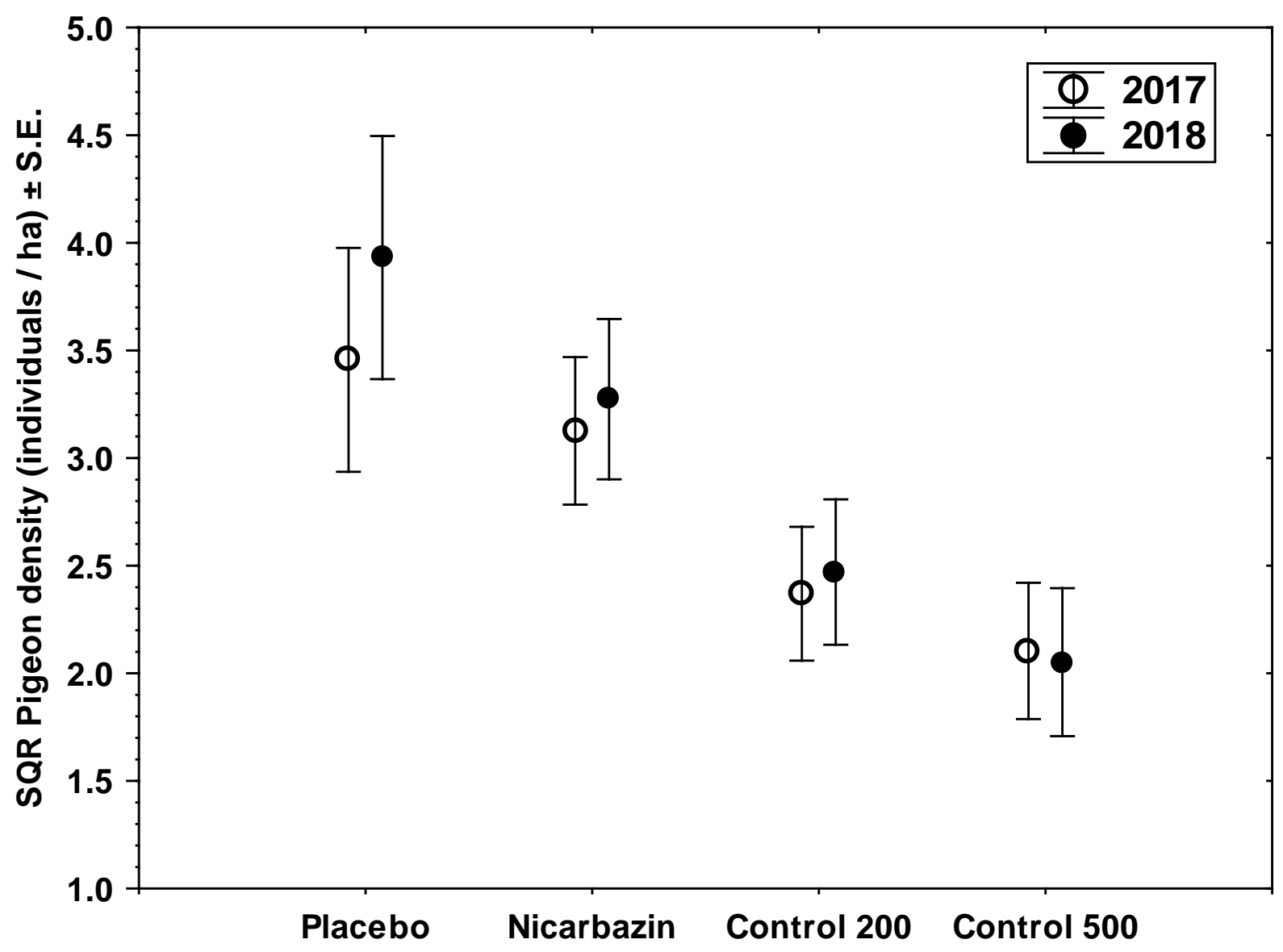

Figure 3. 